\title{
MENORES INFRATORES: PROCESSO DE ESTIGMATIZAÇÃO E O ORDENAMENTO JURÍDICO BRASILEIRO QUANTO PUNIBILIDADE
}

\section{MONOGRAFIA}

NASCENTE, Hanna Karoline ${ }^{1}$

NASCENTE, Hanna Karoline. Menores infratores: processo de estigmatização e - ordenamento jurídico brasileiro quanto punibilidade. Revista Científica Multidisciplinar Núcleo do Conhecimento. Ano 06, Ed. 06, Vol. 13, pp. 108-136. Junho de 2021. ISSN: 2448-0959, Link de acesso: https://www.nucleodoconhecimento.com.br/administracao/menores-infratores, DOI: 10.32749/nucleodoconhecimento.com.br/administracao/menores-infratores

\section{RESUMO}

Para muitos jovens de hoje, os padrões tradicionais que orientam as relações entre família, escola e trabalho estão sendo desafiadas. As relações sociais que garantam um bom processo de socialização estão entrando em colapso. Verifica-se que as trajetórias de estilo de vida estão se tornando cada vez mais variadas e menos previsíveis, por exemplo, a reestruturação do mercado de trabalho, a extensão do hiato de maturidade (o período de dependência de adultos jovens na família) e, sem dúvida, as oportunidades mais limitadas para se tornar um adulto independente. Observa-se que o problema da delinquência juvenil está se tornando cada vez mais complexo, por motivos diversos tais como: os programas de prevenção da criminalidade não saem da teoria; muitos países em desenvolvimento não sabem lidar com a delinquência infantil; e por fim os programas internacionais são em sua maioria insuficientes. Portanto, o objetivo geral desta pesquisa é investigar através de pesquisa bibliográfica as percepções dos adolescentes infratores e o processo de estigmatização e construção psicossocial e os atuais meios jurídicos para esta situação, e, mais especificamente, explorar a vida diária de estigmatização em

\footnotetext{
${ }^{1}$ Pós-graduação em Gestão Pública

RC: 89372

Disponível em: https://www.nucleodoconhecimento.com.br/administracao/menores-infratores
} 
adolescentes, identificar as maneiras pelas quais o estigma em sua construção de identidade opera em sua auto percepção, analisar as formas em que os estereótipos são estigmatizantes e estudar sobre como o âmbito jurídico trata estes indivíduos. Os resultados da pesquisa evidenciam que devem ser alocados mais recursos para a prevenção da droga e abuso de álcool, entre os jovens e o sistema de justiça criminal deve trabalhar com a prevenção, e no último caso, na real reabilitação desses menores. A sociedade, a comunidade, a família, o governo e os pais precisam trabalhar juntos para entender o que as crianças precisam, sabe-se que a realidade atual é difícil em meio a tanta corrupção, crise, desemprego, mas vale lembrar, que a estrutura de um adulto começa na primeira infância em seu seio familiar, onde a maior influência está nas mãos dos pais e na educação.

Palavras-chave: Jovens, Menores infratores, Criminalidade.

\section{INTRODUÇÃO}

Para muitos jovens de hoje, os padrões tradicionais que orientam as relações entre família, escola e trabalho estão sendo desafiados, relações sociais que garantam um bom processo de socialização estão entrando em colapso, trajetórias de estilo de vida tornando-se mais variado e menos previsível, a reestruturação do mercado de trabalho, a extensão do hiato de maturidade (o período de dependência de adultos jovens na família) e, sem dúvida, as oportunidades mais limitadas para se tornar um adulto independente.

Todas essas mudanças influenciam as relações com a família e os amigos, a participação no mercado de trabalho, atividades de lazer e estilos de vida. Não é apenas os países desenvolvidos que enfrentam esta situação, principalmente nos países em desenvolvimento há novas pressões sobre os jovens que passam pela transição da infância para a independência. $\mathrm{O}$ rápido crescimento populacional, a indisponibilidade de habitação e serviços, pobreza, desemprego e subemprego entre os jovens, o declínio das comunidades locais, a superlotação em áreas urbanas pobres, a desintegração da família e sistemas educacionais ineficazes são algumas das pressões com os quais os jovens devem lidar. 
Os jovens de hoje em dia, independentemente do sexo, origem social ou país de residência, estão sujeitos a riscos individuais, mas também estão a ser apresentados a novidades, algumas benéficas e algumas potencialmente prejudiciais. Muitas vezes, a vantagem é das oportunidades ilegais, uma vez que os jovens cometem várias infrações, viciam-se em drogas, e usam a violência contra seus parentes. Dados estatísticos indicam que em praticamente todas as partes do mundo, as taxas de criminalidade juvenil aumentaram nos anos 90 .

A maioria dos estudos e programas que tratam da delinquência juvenil focam na juventude como infratores. Contudo, os adolescentes também são vítimas da delinquência. A ameaça contínua de vitimização é um sério fator na socialização dos jovens e sua internalização das normas e valores da sociedade em geral.

De acordo com dados sobre crimes registrados pela polícia, mais de $80 \%$ de todos os incidentes violentos não são relatados pelas vítimas. Informações sobre as vítimas permite tirar conclusões sobre os infratores também. Resultados de auto- estudos de relatório indicam que uma esmagadora maioria dos que participam infrações contra os jovens têm a mesma idade e o mesmo sexo que as suas vítimas.

A categoria masculina é um marco importante na classificação da pessoa como perigosa (MEDEIROS, 2015). Na maioria dos casos os infratores são homens agindo em grupos, os mais prováveis de se enquadrarem neste perfil estão na faixa etária de 14 aos 19 anos; neste grupo tornando-se vítimas de algum tipo de crime. Pesquisas mostraram que os homens são mais propensos do que as mulheres a se tornarem vítimas.

Os jovens que correm o risco de se tornar delinquentes vivem frequentemente sendo expostos a alguns fatores: alcoolismo parental, desnutrição familiar, superlotação, condições abusivas no domicílio, o flagelo do HIV/SIDA (Síndrome da imunodeficiência adquirida), ou a morte de pais durante conflitos armados; estes se tornam órfãos ou desacompanhados e sem meios de subsistência, habitação e outros meios básicos, as necessidades estão em maior risco de cair na delinquência juvenil. 
O número de crianças em circunstâncias especialmente difíceis, aumentou de 80 milhões para 150 milhões entre 1992 e 2000 (CONDESSO; CONDESSO, 2014).

O problema da delinquência juvenil está se tornando cada vez mais complicado e programas de prevenção da criminalidade ou não estão equipados para lidar com a pressão ou não saem da teoria. Muitos países em desenvolvimento não fizeram lidar com esses problemas, e os programas internacionais são obviamente insuficientes.

Os países desenvolvidos estão envolvidos em atividades voltadas para a prevenção do efeito global, mas estes programas são insuficientes pois seus mecanismos muitas vezes são insuficientes para resolver a situação existente. Em geral, os atuais esforços para combater a delinquência juvenil são justificados pela ausência de uma ação sistêmica e intervenções sociais nestes trabalhos com os infratores e as vítimas, sejam reais ou potenciais. A análise é complicada pela falta de dados comparativos internacionais.

Embasados nestes aspectos tem-se os seguintes problemas: Como os jovens vivenciam este estigma diária? Eles culpam seus responsáveis? Como esses fatores afetam sua construção de identidade? Juridicamente, o que seria viável mudar?

O interesse no assunto que motiva esta pesquisa surgiu em diferentes épocas na faculdade, e devido o período atual a sociedade está em colapso, a violência, a crise, a falta de oportunidades geradas por ela, a discriminação, e a ausência de políticas estruturais, expõem sua vulnerabilidade econômica, a falta de recursos e "exemplos" atuais confundem não só o universo adulto em geral, mais aos mais jovens geram limitações e conflitos.

Como fato político recente sobre a relevância pode ser mencionado o projeto da emenda constitucional para reduzir a idade de responsabilidade criminal. Conduzido sob a premissa de melhorar o cidadão e o lema de segurança para viver em paz. Enquanto este projeto ainda não foi aprovado, esta iniciativa e referenda campanha reforçou o estigma da pobreza e juventude, legitimando a construção social do inimigo 
em delinquentes juvenis, usando em discursos político-partidários insegurança e criminalidade como ferramentas políticas (OLIVEIRA, 2014).

Também é mostrado que considerado "menor" (criminosos ou potencialmente infrator) é dada por olhar e status socioeconômico: ser jovem, pobre, marginalizado, como marcas para conotar perigo (MONTENEGRO, 2013). Os acontecimentos políticos relevantes para os efeitos do grupo de referência a estigmatização não se limita a proposta de emenda constitucional acima mencionado, ao contrário, o sistema político como um todo tem tomado uma série de medidas que resultam na repressão penal e seu aprofundamento. Mas nada se fala sobre a gênese desta criminalidade.

Gerando um processo vitimização secundária, tal que que compõem a sociedade, apesar de não ter sido vítimas de crimes que aumentam percepções de medo e insegurança como se tivéssemos experimentado (ARBESÚN RODRÍGUEZ, 2014), assim jovens pobres são socialmente construídos através de uma ideologia que atravessa a suspeita constante e sensação de tragédia iminente (MORÁS, 2012).

A perda de contato real com estes assuntos, faz "caricaturas parciais de indivíduos que só pode desenhar se forem completados com fragmentos de histórias de tragédias que promovem, avisos ou as piores fantasias jornalística" (MORÁS, 2012, p.147).

Assim, com a criminalização, a vocação é observada como uma rejeição social de tudo o que está ligado aos padrões atuais de socialização dos jovens (ARBESÚN RODRíGUEZ, 2014). É evidente que assim a natureza totalizante do processo de estigmatização seja diariamente enfrentada por jovens pobres.

Do exposto, podemos ver o conceito de pânico moral desenvolvido por Cohen e retomada por Kessler (2011), em que um ato é considerado como uma ameaça, uma vez que um inimigo que incorpora estados, torna-se um à sociedade. "Os pobres são acusados de não fazer o suficiente para si mesmos" (KESSLER, 2011, p. 148).

Assim, as causas e os componentes estão escondidos numa pobreza estrutural e desigualdade, que naturaliza e legitima a desigualdade, atribuindo responsabilidades 
individuais aqueles que vivem em um lugar desfavorecido em um altamente estratificado na estrutura social. Assim este estigma opera como deslocamento das precárias condições de vida e centra-se na periculosidade de certos segmentos da sociedade (FERNANDES, 2012).

No entanto, existem algumas produções que se concentram nos próprios adolescentes em questão, levando seus contos sobre o problema da estigmatização e criminalização caindo sobre seus corpos. $E$ neste sentido que a relevância acadêmica é realçada no que poderia representar a implementação desta pesquisa gerando elementos para a produção de conhecimento sobre um problema de relevância social no país a partir de uma perspectiva pouco estudada.

A estigmatização e criminalização dos adolescentes em situação de vulnerabilidade socioeconômica, como será discutido mais tarde - gera maior desigualdade e vastos impactos negativos sobre este setor da população (MORAES, 2010). Assim, o estudo de como tais estigmas são percebidos e seus impactos subjetivos ao cotidiano desses jovens poderia fornecer insumos valiosos para o desenvolvimento de políticas públicas inclusivas que alvejam tratar e reverter esta situação.

Para entender completamente o estudo da pobreza e em como dar sentido pobre de sua situação é necessário explicar as suas escolhas e decisões. Como vimos, o processo de estigmatização social desenvolvido constrói-se a partir de um imaginário coletivo, cheio de preconceitos, onde a pessoa estereotipada tem como característica única o seu perigo irracional.

A pesquisa busca gerar conhecimento sobre um problema de relevância acadêmico e social dos menores infratores, de modo que procura um desafio para aproximar o leitor às necessidades populares da sociedade.

O desenho metodológico permitirá entendimentos de acesso local e contextuais, e estudou o processo de estigmatização social, colocando adolescentes como protagonistas na produção deste conhecimento, gerando assim um exercício de ouvir a presença real de assuntos que são sistematicamente ignorados como parceiros- 
chave a problemas que a sociedade considera mais importante. Assim, é apresentado como tentativa de fortalecer a cidadania destes jovens.

Espera-se que os resultados desta pesquisa possam contribuir para entrada de insumos para o desenvolvimento de políticas públicas abrangentes para lidar com esse estigma social, e a experiência que cria muito dano ao setor mais fraco da sociedade e ameaçar a coesão social. Também espera-se a estar em maior proximidade e compreensão do âmbito jurídico no tocante a vulnerabilidade socioeconômica.

\section{OBJETIVOS}

\subsection{OBJETIVO GERAL}

O objetivo geral desta pesquisa é investigar as percepções dos adolescentes infratores e o processo de estigmatização e construção psicossocial e os atuais meios jurídicos para esta situação.

\subsection{OBJETIVOS ESPECÍFICOS}

- Identificar as maneiras pelas quais o estigma em sua construção de identidade opera em seu auto percepção,

- Analisar as formas em que os estereótipos são estigmatizantes e estudar sobre como o âmbito jurídico trata estes indivíduos.

\section{METODOLOGIA}

Consistente com os desenvolvimentos teóricos referenciados e os objetivos propostos, a estratégia de investigação metodológica é do tipo qualitativo. Isso ocorre porque o design geral da pesquisa, uma vez que este tipo de metodologia permite 0 ponto de vista da investigação e seu significado. De acordo com a pesquisa exploratória, e sua orientação no sentido de uma perspectiva pouco estudada dos temas abordados, o seu design é flexível, de modo que alguns pontos de suas 
estruturas técnicas e conceituais escolhidos sofrerão mudanças no processo de pesquisa.

No que diz respeito às técnicas de pesquisa, em primeira instância, foi feito pesquisas relativas ao ordenamento jurídico brasileiro, suas lacunas e possíveis melhorias.

\section{O FATOR SOCIAL CONTRIBUITIVO À ESTIGMATIZAÇÃO DE JOVENS}

Para compreender o status socioeconômico da população que se propõem a investigar, isto é, o lugar destes assuntos na estrutura econômica, e como ela é expressa em sociais e subjetivas, termos, tendo desenvolvimentos em (FERNANDES, 2015), vez da noção de exclusão social, propõe três áreas de coesão organizacional ou social: área de integração de vulnerabilidade e desfiliação da área social.

Esta situação é agravada pelo aprofundamento da criminalidade; estamos vivenciando uma falta de preparo policial e violência institucional, em comparação com habitantes adultos (VALE, 2015). Por sua vez estigmatizar as percepções da sociedade, de acordo com Morás (2012, p. 146) exacerbam a exclusão econômica, estabelecendo-se a desconfiança interpessoal e estabelecendo assim um "círculo vicioso onde, fragmentação econômica geracional e territorial, são agravados pelo estigma e rejeição social”.

Agora podemos chegar à razão de elementos desenvolvidos sobre a estigma e identidade juvenil, ainda mais considerando que a adolescência é uma fase nova de subjetividade e conformação de identidade. Goffman (2006) sugere que a sociedade estabelece os meios de categorizar pessoas e atributos que são considerados normais dentro de cada categoria, permitindo localizar um estranho de acordo com as suas aparências, e concentra-se entre o que a sociedade espera do assunto, a sua identidade virtual social e que o assunto é de fato sua identidade social real: 
Existem muitos fatores que contribuem para a criminalidade juvenil, incluindo, educação limitada, baixa frequência escolar, pressão social e de pares, status socioeconômico desfavorecido e abuso de substâncias. Nesta seção exploraremos alguns destes fatores, como eles afetam a juventude e como essas influências negativas podem ser reduzidas.

Os fatores que levam um jovem ao crime podem ser complexos - muitas vezes, uma combinação de fatores interage e se afasta um do outro - e desvendar essas influências negativas pode ser um desafio. Para combater o comportamento criminoso na raiz, é preciso primeiro compreender os amplos fatores sociais, políticos e ambientais que demonstram influenciar este mal comportamento.

\subsection{EDUCAÇÃO INSUFICIENTE}

Desde cedo, o fracasso na escola é um fator importante para prever futuros comportamentos criminosos. De fato, um estudo de 25 anos sobre 1.500 crianças nos bairros de baixa renda da Baixada Fluminense, descobriram que as crianças que frequentavam uma pré-escola de alta qualidade tinham $28 \%$ menos probabilidades de desenvolver problemas de drogas ou serem presas na idade adulta. Além disso, eles eram $22 \%$ menos propensos a ser presos por um crime e $24 \%$ mais propensos a frequentar uma faculdade de quatro anos (CHRISPINO; SANTOS, 2011).

Nas escolas públicas, as crianças experimentam salas de aula superlotadas, falta de professores qualificados e financiamento insuficiente para extras, sem falar na falta de aulas por conta no atraso dos salários dos professores; se as crianças apresentam um desempenho acadêmico fraco, falta de atendimento, expulsão ou abandono escolar, a probabilidade de cometer crime é ampliada.

Deixar a escola cedo reduz a chance de os jovens desenvolverem as habilidades sociais adquiridas na escola, como aprender a cumprir os prazos, seguir as instruções e ser capazes de lidar de forma construtiva com seus pares. Uma criança sem uma educação adequada eventualmente descobrirá que ele ou ela está em desvantagem na força de trabalho. Esse sentimento de desesperança, exacerbado pela ênfase da 
mídia nacional em baixos números de emprego e crises fiscais, podem criar um ambiente predisposto à violência.

\subsection{PRESSÃO SOCIAL}

A adolescência pode ser um momento doloroso de crescer em si mesmo e buscar a aceitação de pares e grupos sociais. Querendo se encaixar e ser aceito, muitas vezes serve de motivação para que os adolescentes sucumbam à pressão dos colegas. Nessa tentativa de se "encaixar", o adolescente, muitas vezes, para parecer descolado, sucumbe às drogas, álcool, sexo; que leva a triste realidade das doenças sexualmente transmissíveis e a gravidez na adolescência.

Em algumas sociedades, especialmente nas áreas do centro da cidade, é comum saber que a atividade dos grupos criminosos é alta e muitos adolescentes se envolvem. O que está se tornando mais compreendido é como a atividade desses grupos, drogas e outras atividades criminosas pode ser profundamente influenciada por essa influência; um fenômeno com o qual o comportamento desviante cometido por um adolescente é transferido ou transmitido para outros adolescentes. Curiosamente, o efeito de ondulação do contágio de pares tem impacto em grupos de adolescentes em áreas geográficas, como bairros, formando posteriormente territórios de facções criminosas.

Filmes, jogos, séries de TV, internet; os veículos de mídia em geral transmitem uma ideia distorcida do mundo real, onde o adolescente pode tudo, domina tudo e a jurisdição releva esta condição etária; a criminalidade, por muitas vezes, é relatada nos filmes de modo ironicamente heroico, passando uma ideia de que o crime nas classes sociais menos favorecidas é justificável; o negro, pobre e morador de favela é deixado de lado pela sociedade e, portanto, a única saída é o crime; as influencias são inúmeras, e a que o adolescente assimila a sua própria vida é a que é considerada mais coerente. 


\subsection{ABUSO DE SUBSTÂNCIA}

O abuso de substâncias por si só pode afetar o desenvolvimento cognitivo, diminuindo as inibições de um jovem e a capacidade de avaliar os riscos. Também é um poderoso contribuinte para o crime quando combinado com outros fatores, que serão descritos a seguir.

\subsubsection{ABUSO E ABSENTISMO ESCOLAR}

O absenteísmo da escola e o uso de drogas são causalmente interligados, à medida que um gera o outro. Os adolescentes que abusam de drogas ou álcool são muito mais propensos a ignorar a escola do que seus colegas não usuários. Os alunos que ignoram a escola são mais propensos a experimentar drogas pela primeira vez ou aumentar o consumo. Esta evasão pode afetar negativamente as notas, o que pode criar um círculo vicioso de baixa educação, baixa autoestima e baixas expectativas para suas futuras carreiras e capacidade de adquirir bens materiais legalmente. Como já estabelecido, o fracasso na escola é um importante fator de risco para os alunos que apresentem futuros comportamentos criminosos, enfrentando prisão e encarceramento (DIAS, 2016).

\subsubsection{MEDICAMENTOS DE PRESCRIÇÃO}

O que pode começar como uma pílula de analgésico "emprestado" de vez em quando tem o potencial real de desenvolver um vício completo. $\mathrm{O}$ acesso fácil a medicamentos que não necessitam de prescrição médica é assombroso. Os adolescentes são muito mais propensos a obter medicamentos gratuitamente de um amigo ou parente do que o comprar de um estranho ou um revendedor e quando a fonte da medicação finda. $O$ adolescente pode utilizar de meios criminosos a fim de sustentar o vício.

E, para os pais que imaginam um vício somente atribuído a drogas ilícitas, fumo ou bebidas alcóolicas, esta realidade é bem mais cambiante; os barbitúricos, analgésicos e outros medicamentos causam dependência, causa danos às vezes irreversíveis a saúde, e sua superdosagem pode levar a morte (LEAL, 2016). 
A adolescência é uma janela crítica de vulnerabilidade aos transtornos por uso de substâncias, porque o cérebro ainda está se desenvolvendo e maleável (uma propriedade conhecida como neuroplasticidade), e algumas áreas do cérebro são menos maduras do que outras. As partes do cérebro que processam sentimentos de recompensa e dor - fatores cruciais para o uso de drogas - são as primeiras a amadurecer durante a infância. $\mathrm{O}$ que permanece incompletamente desenvolvido durante a adolescência é o córtex pré-frontal e suas conexões com outras regiões cerebrais. O córtex pré-frontal é responsável por avaliar situações, tomar decisões acertadas e controlar nossas emoções e impulsos. Normalmente este circuito não é maduro até que uma pessoa esteja em seus 20 e poucos anos (JENSEN, 2016).

O cérebro adolescente é muitas vezes comparado a um carro com um pedal de gás totalmente funcional (o sistema de recompensa), mas com freios fracos (o córtex préfrontal). Os adolescentes são altamente motivados a buscar recompensas agradáveis e evitar a dor, mas suas habilidades de julgamento e tomada de decisão ainda são limitadas. Isso afeta sua capacidade de avaliar os riscos com precisão e tomar decisões acertadas, incluindo decisões sobre o uso de drogas. Por estas razões, os adolescentes são um dos principais alvos das mensagens de prevenção que promovem comportamentos saudáveis e livres de drogas, além de encorajar e capacitar jovens para evitar as tentações de experimentar drogas.

A maioria dos adolescentes não passa de tentar drogas para desenvolver um vício ou outro transtorno por uso de substâncias, no entanto, até experimentar drogas é um problema. O uso de drogas pode fazer parte de um padrão de comportamento de risco, incluindo sexo inseguro, dirigir embriagado ou outras atividades perigosas e não supervisionadas. E nos casos em que um adolescente desenvolve um padrão de uso repetido, pode representar sérios riscos sociais e de saúde, que incluem justamente , o fracasso escolar, problemas com a família e outras relações, perda de interesse em atividades saudáveis normais, memória prejudicada, aumento do risco de contrair uma doença infecciosa (como HIV ou hepatite $\mathrm{C}$ ) por comportamento sexual de risco ou compartilhamento de equipamento de injeção contaminada, problemas de saúde 
mental - incluindo transtornos por uso de substâncias de gravidade variável, risco muito real de morte por overdose, roubo, prisão.

O desenvolvimento do vício é como um ciclo vicioso: o uso crônico de drogas não apenas realinha as prioridades de uma pessoa, mas também pode alterar as principais áreas do cérebro necessárias ao julgamento e autocontrole, reduzindo ainda mais a capacidade do indivíduo de controlar ou interromper o uso de drogas. É por isso que, apesar da crença popular, a força de vontade sozinha é muitas vezes insuficiente para superar um vício. O uso de drogas comprometeu as partes do cérebro que tornam possível "dizer não” (JENSEN, 2016).

Nem todos os jovens correm o mesmo risco de desenvolver um vício. Vários fatores, incluindo predisposições genéticas hereditárias e experiências adversas no início da vida, tornam mais provável o uso de drogas e o desenvolvimento de um transtorno do uso de substâncias. A exposição ao estresse (como abuso físico ou emocional) na infância estimula o cérebro a ser sensível ao estresse e a buscar alívio durante toda a vida; isso aumenta muito a probabilidade de abuso subsequente de drogas e de iniciar o uso de drogas precocemente.

De fato, certas características que colocam uma pessoa em risco de uso de drogas, como ser impulsivo ou agressivo, manifestam-se bem antes do primeiro episódio de uso de drogas e podem ser abordadas por intervenções de prevenção durante a infância. Da mesma forma, uma série de fatores, como a educação dos filhos ou um ambiente escolar saudável, pode estimular o desenvolvimento saudável e, assim, diminuir o risco de uso posterior de drogas.

Os sérios riscos para a saúde das drogas agravam a necessidade de levar o adolescente que está abusando de drogas ao tratamento o mais rápido possível. Além disso, os adolescentes que estão abusando de drogas provavelmente terão outros problemas, como problemas de saúde mental, acompanhando e possivelmente contribuindo para o uso de substâncias, e estes também precisam ser abordados. Infelizmente, menos de um terço dos adolescentes internados em 
tratamento de abuso de substâncias psicoativas que têm outros problemas de saúde mental recebem qualquer cuidado pelas suas condições (ALENCAR, 2009).

Os adolescentes também podem ter menos probabilidade do que os adultos de sentir que precisam de ajuda ou de procurar tratamento por conta própria. Dadas as suas histórias mais curtas de uso de drogas (bem como a proteção dos pais), os adolescentes podem ter experimentado relativamente poucas consequências adversas de seu uso de drogas; seu incentivo para mudar ou engajar-se no tratamento pode corresponder ao número de tais consequências que eles sofreram. Além disso, os adolescentes podem ter mais dificuldade do que os adultos em verem seus próprios padrões de comportamento (incluindo causas e consequências de suas ações) com distanciamento suficiente para dizer que precisam de ajuda.

Qualquer que seja a idade de uma pessoa, o tratamento não é "tamanho único". É necessário levar em consideração as necessidades de toda a pessoa - incluindo seu estágio de desenvolvimento e habilidades cognitivas e a influência da família, amigos e outras pessoas na vida da pessoa, bem como quaisquer condições adicionais de saúde mental ou física. Tais questões devem ser abordadas ao mesmo tempo que o tratamento de uso de substâncias. Ao tratar adolescentes, os médicos também devem estar prontos e aptos a lidar com as complicações relacionadas à confidencialidade de seus pacientes jovens e sua dependência de membros da família que podem ou não apoiar a recuperação.

Quando os transtornos por uso de substâncias são identificados e tratados na adolescência - especialmente se forem leves ou moderados - eles frequentemente dão lugar à abstinência de drogas sem mais problemas.

A recaída é uma possibilidade, no entanto, como acontece com outras doenças crônicas, como diabetes ou asma. A recaída não deve ser vista como um sinal de que o tratamento falhou, mas como uma ocasião para se envolver em tratamento adicional ou diferente. 
Evitar e detectar recaídas envolve o acompanhamento por parte do adolescente, pais e professores, bem como acompanhamento pelos provedores de tratamento. Embora os programas de apoio à recuperação não sejam um substituto para o tratamento formal baseado em evidências, eles podem ajudar alguns adolescentes a manter um estilo de vida positivo e produtivo livre de drogas que promova relacionamentos significativos e benéficos e conexões com a família, colegas, e a comunidade durante o tratamento e depois do tratamento terminam. Quaisquer que sejam os serviços ou programas utilizados, o caminho para a recuperação de um adolescente será reforçado pelo apoio de familiares, colegas que não usam drogas, a escola e outros em sua vida (TEIXEIRA, 2014).

\subsection{FALTA DE ORIENTAÇÃO MORAL}

Os atos de crime são ações moralmente inatas e, como tal, as crianças aprendem o conceito do que é errado seguindo os exemplos adultos durante a infância - de seus pais, se os pais estão presentes na família, dos avós, membros da família nuclear, grupos sociais e outras influências autoritárias. Na ausência desses adultos preocupados e na falta também de influências positivas, uma criança pode sofrer de "pobreza moral" que tem a capacidade de acompanhar uma criança na adolescência e na idade adulta jovem. A pobreza moral engendra superpredadores juvenis cujo comportamento é conduzido por dois defeitos de desenvolvimento. Primeiro, eles estão radicalmente orientados para o presente; eles vivem inteiramente no momento presente. Em segundo lugar, os superpredadores são radicalmente egoístas; eles não colocam valor na vida de suas vítimas.

Se uma criança não é ensinada durante esses anos formativos para exibir as seguintes ações morais, ele ou ela pode mais tarde recorrer ao crime simplesmente porque o ato não parece errado ou imoral. O motivador do crime, nesses casos, pode ser uma ameaça percebida; no entanto, pode ser tão facilmente um fracasso ou uma incapacidade aprendida para fazer a distinção moral entre certo e errado.

A violência doméstica, a falta de estrutura familiar, gravidez precoce, desemprego e abuso de substâncias ilícitas praticadas perto de uma criança, pode gerar danos 
morais eternos. Todos esses fatores geram abandono, depressão, pobreza extrema e sem uma base familiar correta, essa criança tende a seguir a mesma linhagem de seus pais ou tutores, enriquecendo assim, mais ainda o índice de menores infratores.

Pais tóxicos, também são um dos fatores para uma vida desregrada, e cheia de problemas na vida do jovem. Há muitas famílias assim. Pais tóxicos são pais que não contribuem para o desenvolvimento social e psicológico dos filhos, pois muitas vezes o rejeitam.

As vezes a rejeição passa a ser um fator de violência nessa relação. Além dos mal tratos psicológicos, essa rejeição pode se tornar física. A maioria dos jovens revoltados, usuários de drogas ou substâncias convivem com este tipo de relacionamento. É um relacionamento depreciativo, onde a criança é constantemente bombardeada com ofensas de ordem moral que afetam o psicológico, o desenvolvimento mental e a sociabilidade levando a problemas em seus relacionamentos futuros, depressão, comportamento violento, desvio de caráter e até suicídio.

A influência exteriorizada também afetar o fator dinâmico educacional dos jovens, a política corrupta, a crise, as leis, fazem parte do que deveria ser a solução para as classes menos favorecidas, na verdade, é um dos maiores vilões da sociedade, a começar pela influência; roubam, matam, mentem em nome do poder.

No presente estudo, menores infratores estão compreendidos na faixa etária entre 1218 anos, o que é categorizada como a idade adolescente. Em uma comunidade estes adolescentes cometem delitos como roubo, assassinato, estupro, e ainda se viciam em drogas ilícitas, fumo, álcool e também medicamentos.

Além das mudanças incontestáveis e crescimento do adolescente, biologicamente e psicologicamente, a adolescência apresenta três características essenciais, tais como o desenvolvimento de autoconsciência, afirmando a sua identidade, integração social. Um senso de certo e errado, normativa e motivacional, orientada para negar e rejeitar os modelos adultos e pesquisar seu próprio estilo de vida, reflete a personalidade 
instável de um adolescente. Não é só o fator individual que é responsável por inadimplência ou crime, mas são os fatores multidimensionais que são responsáveis pela delinquência. Devido à complexidade do comportamento humano e os vários fatores multicausais, o melhor caminho para o progresso no campo da criminologia é através da combinação de fatores multidisciplinares, onde envolve a nível micro e macro nível.

A interação de uma criança dentro da família também tem uma maior influência sobre a delinquência. Pesquisas empíricas no campo da delinquência juvenil sugere que, uma supervisão adequada, educação e formação na escola, bem como valores em casa, contribui positivamente para a eliminação dessas crianças no mundo da criminalidade. Isto é considerado que os pais e os professores desempenham um papel crucial no desenvolvimento real e crescimento do caráter de uma criança; tendo isso em vista que eles podem ajudar a reduzir a ocorrência de incidência deplorável.

A violência aumenta dramaticamente na segunda década da vida, atingindo um pico no final da adolescência em 12 a $20 \%$ de todos os jovens e caindo bruscamente no início dos anos vinte. Alguns desses jovens seguiram a trajetória de início da infância, tornando-se violentos antes da puberdade e aumentando sua taxa de ofensas durante a adolescência. Mas mais de metade de todos os jovens violentos começam seu comportamento violento no meio da adolescência. Esses jovens deram pouca indicação de comportamento problemático na infância e não tiveram relações precárias com seus pais (CAVALCANTE; ALVES; BARROSO, 2008).

A transição para a adolescência começa a se mover para a independência dos pais e a necessidade de estabelecer os próprios valores, a identidade pessoal e sexual e as habilidades e competências necessárias para competir na sociedade adulta. A independência exige que os jovens renegociem as regras da família e o grau de supervisão dos pais, um processo que pode gerar conflitos e retirada dos pais. Ao mesmo tempo, as redes sociais se expandem e as relações com colegas e adultos em novos contextos sociais são iguais ou superiores às relações com os pais. Os critérios de sucesso e aceitação entre colegas e adultos mudam. 
A adaptação a todas essas mudanças nos relacionamentos, contextos sociais, status e critérios de desempenho pode gerar grande estresse, sentimento de rejeição e raiva no fracasso percebido ou real. Os jovens podem ser atraídos por comportamentos violentos como uma forma de afirmar sua independência do mundo adulto e suas regras, como forma de ganhar a atenção e o respeito dos pares, como forma de compensar competências pessoais limitadas ou como resposta a oportunidades restritas de sucesso na escola ou na comunidade. As boas relações com os pais durante a infância ajudarão a uma transição bem-sucedida para a adolescência, mas não o garantem.

Os adolescentes expostos à violência em casa podem experimentar algumas das mesmas emoções e dificuldades que as crianças mais jovens em idade escolar - por exemplo, medo, culpa, ansiedade, depressão e dificuldade em se concentrar na escola. Além disso, os adolescentes podem se sentir mais vulneráveis à violência de colegas na escola ou gangues em seu bairro e sem esperança sobre suas vidas e suas chances de sobreviver até a idade adulta. Esses jovens podem não experimentar os crescentes sentimentos de competência que são importantes em seu estágio de desenvolvimento. Em última análise, sua exposição à violência pode levá-los a se tornarem também violentos. Estudos demonstraram que os adolescentes expostos à violência são mais propensos a se envolverem em atos violentos, muitas vezes como ataques preventivos diante de uma ameaça percebida.

Não surpreendentemente, diferentes fatores de risco para a violência assumem importância na adolescência. Os fatores familiares perdem valor preditivo em relação a fatores de risco orientados para pares, como laços sociais fracos com colegas convencionais, amigos antissociais ou delinquentes e associação em uma associação criminosa. Mesmo o envolvimento em infrações gerais, que teve o maior tamanho de efeito na infância, tem apenas um tamanho de efeito moderado na adolescência.

No início da adolescência, o envolvimento em ofensas gerais - ou seja, atos ilegais, mas não necessariamente violentos, incluindo crimes - torna-se um fator de risco moderado para violência entre 15 e 18 anos. Seu poder preditivo diminui desde a 
infância, principalmente porque os adolescentes são um pouco mais prováveis do que as crianças se envolverem em comportamentos ilegais (OLIVEIRA, 2015).

As condições psicológicas, nomeadamente a agitação, a dificuldade de concentração e a tomada de riscos, têm pequenos efeitos na adolescência. A falta de preocupação e a dificuldade de concentração podem afetar o desempenho na escola, um fator de risco cuja importância aumenta ligeiramente na adolescência. A tomada de risco ganha poder preditivo no início da adolescência, particularmente em combinação com outros fatores. Um jovem imprudente que vê a violência como um meio de expressão aceitável, por exemplo, é mais provável que se envolva em comportamentos violentos.

A agressividade exerce efeito na violência posterior entre os adolescentes do sexo masculino, pelo simples fato de ter nascido homem. Embora a agressividade seja incomum em crianças entre as idades de cerca de 6 e 10, não é terrivelmente incomum na adolescência. Da mesma forma, a violência física e os crimes contra pessoas no início da adolescência têm um pequeno efeito sobre a probabilidade de violência entre 15 e 18 anos.

As atitudes e crenças antissociais, incluindo a hostilidade em relação à polícia é uma atitude positiva em relação à violência, e são preditores mais importantes entre meninos do que em meninas.

O uso de substâncias, é um forte preditor de violência posterior para crianças, pois os leva a roubo, violência e seu ingresso ao mundo do crime. A maioria dos infratores adolescentes violentos usa álcool e drogas ilícitas. O uso ilícito de drogas tende a começar após o início da violência e a ser associado a comportamentos violentos mais frequentes e a uma carreira criminal mais longa. O uso de drogas pode contribuir para a violência contínua, e não para o aparecimento da violência, mas está longe de ser conclusivo. O comportamento violento provém de roubos ou outras tentativas de obter dinheiro para sustentar um hábito de drogas, bem como homicídios.

A influência direta dos pais sobre o comportamento é amplamente um fator de grande importância tanto na infância quanto na adolescência. 
Um relacionamento familiar abusivo, a falta de estrutura social e psicológica dos pais em relação ao menor contribuem efetivamente para o processo de marginalização. Embora os pais possam e influenciem o comportamento de seus adolescentes, eles fazem isso em grande parte indiretamente. A falta de estrutura psicológica os impede de perceber o ambiente que está criando para essas crianças, talvez por que também tiveram a mesma base educacional na família.

A cultura de violência em algumas escolas, evidenciada por inúmeros ataques de facções criminosas a seus rivais e também a policiais afetam adversamente não apenas os alunos, mas os professores, pais, comunidade e o estado como um todo. Os estudantes expostos à violência na escola podem reagir ao permanecer em casa para evita-la ou impulsionar a mais violência, influenciando a o uso de armas para autodefesa. Por sua vez, os professores podem sofrer de transtornos psicológicos depois de anos lidando com problemas de disciplina e ameaças de violência.

As escolas localizadas em bairros socialmente desorganizados são mais propensas a ter uma alta taxa de violência do que as escolas em outros bairros. As escolas localizadas nas áreas de risco sofrem quase que diariamente com a violência, proporcionando greves e evasão escolar, estes fatores enriquecem os dados de analfabetismo, desemprego e falta de oportunidades que são a chave para a violência.

Os grupos sociais são muito importantes na adolescência. Os adolescentes que têm laços sociais fracos - ou seja, que não estão envolvidos em atividades sociais convencionais e são impopulares na escola - correm alto risco de se tornarem violentos, assim como os adolescentes com colegas antissociais e delinquentes. Esses dois tipos de relacionamentos geralmente caminham juntos, já que os adolescentes que são rejeitados ou não são populares com colegas convencionais podem encontrar rejeição, discriminação e através de fatores como o bullying se tornarem violentos. $\mathrm{O}$ isolamento social, a exclusão engloba uns dos diversos fatores contribuintes para a infratoriedade do menor.

O aumento do envolvimento na comunidade é uma parte saudável do desenvolvimento de adolescentes, a menos que a própria comunidade represente 
uma ameaça à saúde e à segurança. A desorganização social e a presença de crime e drogas no bairro representam riscos de violência.

As comunidades socialmente desorganizadas são caracterizadas, em parte, pelo fluxo econômico e social, pelo alto volume de negócios dos moradores e por uma grande proporção de famílias desabrigadas ou monoparentais, o que diminui a probabilidade de adultos estarem envolvidos em redes informais de controle social. Como resultado, geralmente há pouco conhecimento ou supervisão de adultos das atividades de adolescentes e uma alta taxa de criminalidade. Além disso, em áreas com declínio econômico, é provável que haja poucos negócios do bairro. Em tal ambiente, é difícil para os jovens evitarem serem atraídos para a violência. Pois nesses lugares, pouco se faz para que esses jovens se envolvam em atividades físicas ou algo que enriqueçam o seu currículo.

A desorganização social também é um fator de risco para a violência nas áreas rurais. Um estudo de comunidades rurais descobriu que a pobreza desempenha um papel menos importante na predição da violência do que a instabilidade residencial, e outros indicadores de desorganização social. De fato, áreas muito pobres não se caracterizaram por uma alta instabilidade residencial. Nas cidades, no entanto, a combinação de pobreza com instabilidade e ruptura familiar é preditiva de violência.

Os adolescentes que estão expostos à violência em seu bairro se sentem vulneráveis e incapazes de controlar suas vidas. Esses sentimentos podem levar a desamparo e desesperança. Tais jovens podem recorrer à violência como forma de afirmar o controle sobre seus arredores. Eles podem se armar ou até juntar-se a grupos criminosos para proteção.

Os adultos da vizinhança envolvidos no crime representam um risco porque os jovens podem imitá-los. Medicamentos facilmente disponíveis aumentam o risco de violência. 


\section{A REALIDADE DO ORDENAMENTO JURÍDICO BRASILEIRO QUANTO A PUNIBILIDADE DOS MENORES INFRATORES, EDUCAÇÃO E FATORES DIVERSOS}

Com a violência ao extremo em nosso estado, causada por diversos fatores que variam da realidade pobre nas classes menos favorecidas, a falta de pagamento aos profissionais da segurança, vivemos numa verdadeira guerra civil. Infelizmente, muito do que nos amedronta ainda não completou 18 anos; é, essa triste realidade se tornou algo banalizado.

De acordo com a lei existente, os delinquentes com idades compreendidas entre os 12 e os 18 anos devem ser tratados através do serviço comunitário ou da educação, com uma pena máxima de até três anos em um centro de detenção pelos crimes mais graves. Na realidade, no entanto, os jovens que cometem infrações menores são muitas vezes trancados em instalações superlotadas com escassas oportunidades de reabilitação e educação, ou proteção contra maus tratos, e o ciclo da violência apenas segue seu curso contínuo (COUTO, 2012).

De acordo com a Comissão dos direitos humanos, em 2014 cerca de 22 mil jovens no Brasil foram alojados em centros de detenção juvenil, que foram projetados para manter um máximo de 18 mil. Mas a superlotação é apenas um aspecto de um regime que as inspeções encontraram; jovens encarcerados por horas em salas minúsculas, com poucas oportunidades de recreação - condições que provocam, rebeliões, gerando mais e mais violência (ANDRADE, 2017).

A polícia além das péssimas condições de trabalho, se sentem com as mãos "atadas" em relação a punibilidade destes menores. As leis proíbem penas mais severas, mas, de outro lado não contribui para que esta violência pare; de um lado, jovens que se sentem a cima das leis praticam todo o tipo de criminalidade que varia de pequenos furtos até latrocínios (roubo seguido de morte), e de outros governantes omissos a investir numa educação de qualidade e geração de recursos para que estes jovens 
possam sair da linha da pobreza extrema. O famoso "jeitinho" brasileiro para tudo, contribui para uma sociedade desonesta e sem princípios.

Até as políticas de educação e suas diretrizes são uma farsa. O IDEB - Índice de Desenvolvimento da Educação Básica, que deveria implantar um sistema que realmente melhorasse a qualidade de educação, impõe às escolas públicas que, crianças não podem ser reprovadas e que de imediato, em sua primeira avaliação não podem receber a nota máxima, para que, ao final do ano letivo, haja um crescimento simulado para justificar o crescimento no estudo e para que não caia os índices de aprovação. Como podemos observar, não passa de mais uma manobra para mitigar um problema que está longe de ser solucionado (BUENO, 2016).

Como resultado desta falta de responsabilidade governamental, jovens são levados a essas casas de reabilitação, que na verdade em nada devolve este jovem recuperado; salas em condições precárias de higiene, superlotação, falta de medidas socioeducativas, doença, abandono, fome; a realidade que muitas vezes o leva a estes lugares, permanece presente em sua fase de encarceramento.

Deve-se na verdade, prevenir o crime, não o financiar. Investir nos fatores socioeconômicos evita futuramente de investir em mais estruturas carcerárias.

O senado examina uma emenda constitucional para permitir que jovens de 16 e 17 anos acusados de crimes graves sejam julgados e punidos como adultos. Uma lei separada elevaria o tempo máximo de internação para crianças de três a dez anos. $O$ nosso país enfrenta um verdadeiro dilema quanto a isto. A verdade é que nem os governantes, e nem a população estão preparadas para mudanças. A maioria dos brasileiros, especialmente nas elites e as classes médias, estão convencidos de que o crime pode ser reduzido através do encarceramento em massa, e esta superlotação contribui para que haja reincidência.

$\mathrm{Na}$ verdade, os adolescentes eram a faixa etária mais susceptível de serem mortos durante o crime. A prisão de jovens negros tem sido especialmente significativa na condução de taxas aumentadas de encarceramento, a discriminação ainda presente 
na sociedade traz dificuldades em acessar direitos e oportunidades, e a falta de reabilitação em centros de detenção leva invariavelmente a uma vida de prisão.

O sistema jurídico criminal traça em seu sistema, um perfil pré-determinado sobre o traficante, o assaltante e o homicida. Geralmente, jovens, negros, moradores de comunidades, fora da escola são para eles o retrato da criminalidade. O jovem pobre, não tem condições de custear uma ajuda jurídica e por isso presencia mais anos no sistema prisional. E quando este indivíduo é devolvido a sociedade, enfrenta novamente o descaso, a falta de oportunidades e a discriminação é ativa, e o ciclo da criminalidade continua intermitentemente.

A pesquisa sobre a resiliência e a abordagem da saúde pública para o problema da violência juvenil trouxe uma nova conscientização e pesquisa sobre fatores de proteção - aqueles aspectos do indivíduo e seu ambiente que amortecem ou moderam o efeito do risco. Identificar e compreender como fatores de proteção operam é potencialmente tão importante para a prevenção da violência e esforços de intervenção como pesquisa sobre fatores de risco.

Até à data, a evidência relativa aos fatores de proteção contra a violência não atendeu aos padrões estabelecidos para os fatores de risco. Portanto, esta seção não se refere a fatores de proteção, apenas aos fatores de proteção propostos. Existem vários motivos para isso: nem todos os estudos definem fatores de proteção como amortecimento dos efeitos do risco; a maioria dos estudos procurou um efeito sobre o comportamento antissocial em geral, e não sobre a violência especificamente; e aqueles que encontraram efeitos tamponantes sobre a violência não foram adequadamente replicados. Isso não significa que fatores de proteção não existam, apenas que é necessária mais pesquisa para identificá-los.

A maioria dos estudos de fatores protetores não especifica quando, em curso de desenvolvimento, esses fatores exercem seus efeitos de amortecimento ou como eles mudam ao longo da vida. É necessário um estudo mais aprofundado para esclarecer esses pontos. 
Uma atitude intolerante em relação ao desvio, incluindo o comportamento violento, é o fator de proteção proposto mais forte. Isso reflete um compromisso com os valores e normas tradicionais, bem como a desaprovação de atividades que violam essas normas. É improvável que os jovens cujas atitudes sejam antitéticas da violência se envolvam em atividades que possam levar à violência ou associar-se a colegas que são delinquentes ou violentos.

O nascimento feminino também pode ser um fator positivo. Ser uma menina implica menos exposição à violência, menos impulsividade e ousadia, e espera-se que se comporte menos agressivamente do que os meninos.

Não há dúvida de que um aspecto essencial do desenvolvimento saudável da criança está formado a um apego seguro na infância a um pai ou outro adulto que sente e responde às necessidades de um bebê. Um adulto amoroso, interessado em apoiar as ideias e atividades de uma criança ou jovem ajuda a criança ou adolescente a desenvolver a confiança e a competência necessárias para passar de um estágio de desenvolvimento para outro. As boas relações com um adulto que apoia o comportamento convencional e desaprovam o comportamento delinquente podem fornecer uma orientação inestimável para os jovens. A questão é se essas relações modificam os efeitos da exposição ao risco e, portanto, se encaixam na definição de um fator de proteção.

Um relacionamento caloroso e de apoio com pais ou outros adultos demonstrou proteger contra o comportamento antissocial, mas estudos até agora não encontraram um efeito tamponante significativo sobre o risco de violência (CIA et al, 2006).

Não é certo se fatores de proteção familiar, como fatores de risco familiares, se tornam menos influentes à medida que os jovens progridem na adolescência. $\mathrm{O}$ apoio e o encorajamento dos pais permanecem importantes, mas mesmo os pais tenham um bom relacionamento com seus filhos os livram da criminalidade. Fatores externos também impulsionam a este tipo de comportamento. 
O compromisso com a escola é o segundo fator de proteção proposto que foi encontrado para amortecer o risco de violência juvenil. Os jovens que estão comprometidos com a escola abraçam os objetivos e os valores de uma instituição social influente. É improvável que tais jovens se envolvam em violência, tanto por ser incompatível com sua orientação quanto por comprometer sua realização na escola e sua posição com adultos. Este fator proposto está incluído porque parece amortecer o risco de violência, não porque seja o oposto de uma atitude ou comportamento fraco na escola, mais um horizonte esperançoso na formação cultural do adolescente.

A escola pode dar aos adolescentes que enfrentam múltiplos fatores de risco um lugar para se destacar social e academicamente. A realização na escola e a aprovação dos professores proporcionam o reconhecimento tão importante para o desenvolvimento de adolescentes - o reconhecimento que algum adolescente não recebe de outras fontes. $O$ incentivo dos professores pode dar aos jovens a confiança para buscar treinamento contínuo em treinamento educacional ou profissional. Além disso, as escolas com grupos de pares que valorizam a realização acadêmica podem reduzir o risco dos alunos de se envolverem na violência. Infelizmente, as escolas com cultura de violência podem ser incapazes de exercer sua função de proteção, pois dependem de diversos fatores.

As atividades extracurriculares em arte, música, teatro, publicações escolares e outros, proporcionam aos adolescentes a oportunidade de participar de atividades grupais construtivas e de obter reconhecimento pelos seus esforços. A interação, de pais, professores, escola e comunidade podem contribuir para que as crianças encontrem na escola a chance de reverter esse triste quadro, que é a violência e a detenção de menores.

Ter amigos que se comportam convencionalmente é um fator de proteção proposto que parece reduzir o risco de delinquência, mas não há evidência de um verdadeiro efeito de amortecimento em fatores de risco específicos. Pais que atuam ativamente na vida social de seus filhos também ajudam a reduzir índices de violência. 


\section{CONSIDERAÇÕES FINAIS}

A presente pesquisa abordou sobre os menores infratores, foi descrito sobre os fatores de risco, a posição das governantes perante a esta problemática e ao final, foi recomendado estratégias que não só agissem com efeitos tamponantes, e sim preventivos.

Criar um filho não é fácil, é um trabalho de tempo integral que requer uma grande dose de atenção, e não oferecendo nenhuma garantia de que a criança vai se tornar um membro produtivo da sociedade como um adulto maduro. As crianças não têm a capacidade de entender que mentir, roubar, enganar e ferir os outros são comportamentos errados, então, cabe a nós, pais, a ensinar valores.

A idade em que uma criança atinge a fase de raciocínio varia de acordo com a forma como se desenvolve e o ambiente que se é educada. As crianças às vezes aprendem a razão pela observação do comportamento das pessoas mais importantes para elas. No entanto, não há nenhuma garantia. Às vezes, as crianças seguem seus próprios ditames.

A sociedade, a comunidade, a família, o governo e os pais precisam trabalhar juntos para entender o que as crianças precisam. Comunidades devem se esforçar para incorporar jovens em funções sociais na comunidade, e a polícia também pode desempenhar um papel mais ativo nas comunidades, ou seja, falando em escolas e participando de funções locais, palestras; é preciso tirar da cabeça das crianças que vivem nestas comunidades a imagem de policiais cruéis e implacáveis, e recoloca-los na posição de protetores da sociedade.

A delinquência está associada a um mau desempenho escolar, ausência escolar e abandono escolar em uma idade jovem. Algumas práticas pedagógicas podem agravar esses problemas. A pesquisa disponível sobre retenção e rastreamento de notas e as práticas disciplinares de suspensão e expulsão revelam que essas políticas têm efeitos mais negativos do que positivos. Para os estudantes que já experimentam dificuldades acadêmicas, o rastreamento e a retenção de notas foram encontrados 
para prejudicar ainda mais seu desempenho acadêmico. Além disso, o rastreamento não parece melhorar o desempenho acadêmico dos alunos em trilhas altas em comparação com estudantes similares em escolas que não usam rastreamento. Suspensão e expulsão negam a educação em nome da disciplina, mas essas práticas não se mostraram eficazes na redução do mau comportamento escolar. Pouco se sabe sobre os efeitos dessas políticas em outros alunos da escola. Dado que as políticas afetam desproporcionalmente as minorias, essas políticas podem involuntariamente reforçar os estereótipos negativos, deve ser realizada uma revisão completa dos efeitos das políticas escolares e das práticas pedagógicas, tais como retenção de classificação, rastreamento, suspensão e expulsão. Esta revisão deve incluir os efeitos de tais políticas na delinquência, bem como os efeitos sobre o nível de escolaridade e a atmosfera e o ambiente da escola.

A exposição precoce ao álcool, à cocaína, à heroína e à nicotina está associada à hiperatividade, déficit de atenção e impulsividade, que são fatores de risco para o comportamento antissocial posterior e a delinquência. Aos insultos biológicos sofridos durante 0 período precoce podem ter alguns efeitos devastadores no desenvolvimento.

O período natal, como a prevenção da exposição fetal ao álcool e às drogas, pode ter grandes benefícios. Reduzir o abuso de álcool e drogas entre os pais expectantes também pode melhorar sua capacidade de progenitores, reduzindo fatores de risco relacionados à família para a delinquência. Os governos federais, estaduais e locais devem atuar para fornecer tratamento para o abuso de drogas (incluindo o consumo de álcool e tabaco) entre mulheres grávidas, em particular adolescentes.

A maioria dos estudos longitudinais de comportamento delinquente começam depois que as crianças entram na escola. No entanto, o desenvolvimento anterior parece contribuir para problemas que se tornam evidentes durante os primeiros anos escolares. Resta muito saber sobre a medida em que os problemas potenciais podem ser identificados em uma idade precoce. 
A pesquisa mostrou que quanto maior o número de fatores de risco que estão presentes, maior a probabilidade de delinquência. Além disso, o tempo, a gravidade e a duração dos fatores de risco, em interação com a idade, gênero e o ambiente em que o indivíduo vive, sem dúvida, afetam os resultados comportamentais. Uma melhor compreensão de como os fatores de risco interagem é importante para o desenvolvimento de esforços de prevenção, especialmente os esforços em comunidades nas quais os fatores de risco estão concentrados.

A pesquisa sobre fatores de risco para a delinquência precisa se concentrar nos efeitos das interações entre vários fatores de risco. Em particular, a pesquisa sobre os efeitos das diferenças nos bairros e suas interações com as condições individuais e familiares deve ser expandida.

A pesquisa sobre a delinquência tradicionalmente se concentrou em meninos. Embora os meninos sejam mais propensos a serem presos do que as meninas, a taxa de aumento na prisão e no encarceramento tem sido muito maior nos últimos anos para meninas do que para meninos e a gravidade dos crimes cometidos por meninas aumentou.

Mais recursos devem ser alocados em nosso estado para a prevenção da droga e abuso de álcool, entre os jovens e o sistema de justiça criminal deve trabalhar com a prevenção, e no último caso, na real reabilitação desses menores. Investimentos em educação gera mais espaços nas cadeias, logo não existirá superlotação, violência e reincidência.

A realidade é difícil em meio a tanta corrupção, crise, desemprego, mas a estrutura de um adulto começa na primeira infância em seu seio familiar, onde a maior influência está nas mãos dos pais e na educação. 


\section{REFERÊNCIAS}

ALENCAR, Henedina Freitas de. Perfil dos usuários em tratamento no centro de atenção psicossocial-álcool e drogas. 2009. 83 f. Projeto (Graduação em Enfermagem) - Universidade Católica de Brasília, 2009.

ANDRADE, Aedra Sarah de. "Aqui as flores nascem no concreto": negociações nas atuações laborais de agentes socioeducativos. 2017. xv, 161 f., il. Dissertação (Mestrado em Processos de Desenvolvimento Humano e Saúde) - Universidade de Brasília, Brasília, 2017.

ARBESÚN RODRÍGUEZ, Rolando. ¿Acaso no matan a los caballos?: configuraciones punitivas y escenario empírico de las infracciones a la Ley Penal en adolescentes. 2014. 151 f. Tesis (Magister en Psicología Social) Universidad de la República, Montevideo, Uruguay, 2014.

BUENO, Angélica Alves. Sonhos alheios: contornos e limites da (re)organização do sistema escolar brasileiro, Catalão (GO) 1990-2015. 2016. 152 f. Dissertação (Mestrado Profissional em História) - Universidade Federal de Goiás, Catalão, 2016.

CAVALCANTE, Maria Beatriz de Paula Tavares; ALVES, Maria Dalva Santos; BARROSO, Maria Grasiela Teixeira. Adolescência, álcool e drogas: uma revisão na perspectiva da promoção da saúde. Escola Anna Nery, v. 12, n. 3, p. 555-559, set. 2008.

CHRISPINO, Álvaro; SANTOS, Tais Conceição Dos. Política de ensino para a prevenção da violência: técnicas de ensino que podem contribuir para a diminuição da violência escolar. Ensaio: Avaliação e Políticas Públicas em Educação, v. 19, n. 70, p. 57-80, mar. 2011.

$\mathrm{CIA}$, Fabiana et al. Habilidades sociais parentais e o relacionamento entre pais e filho. Psicologia em Estudo, Maringá, v. 11, n. 1, p. 73-81, jan. /abr. 2006. 
CONDESSO, Catarina Alexandra de Azevedo dos Reis; CONDESSO, Fernando. A proteção das crianças e jovens em perigo no direito contemporâneo. Revista Jurídica do Instituto Superior Manuel Teixeira Gomes, Portimão, n. ํ 4, p. 35-77, mai. 2014

COUTO, Isabel Luís do. O problema da idade da imputabilidade penal. Porto. 2012. 59 f. Tese (Mestrado em Direito) - Universidade Católica Portuguesa, Porto, 2012.

DIAS, Tamille Sales. Entre ausências, incertezas e labirintos: a inserção social de jovens que não trabalham nem estudam no Brasil. 2016. 132 f., il. Dissertação (Mestrado em Desenvolvimento, Sociedade e Cooperação Internacional) Universidade de Brasília, Brasília, 2016.

FERNANDES, Ana Isabel Lapa. Visões da pobreza na primeira pessoa Contributos para o Entendimento do Fenómeno Social da Pobreza na Cidade de Beja. 2012. 883 f. Tese (Doutorado em Serviço Social) - Universidade Católica Portuguesa, Porto, jun. 2012.

FERNANDES, Florestan. Mudanças sociais no Brasil. São Paulo: Global Editora e Distribuidora Ltda, 2015.

GOFFMAN, Erving. Estigma: la identidad deteriorada. Buenos Aires: Amorrortu, 2006.

JENSEN, Frances E.; NUTT, Amy Ellis. O cérebro adolescente: guia de sobrevivência para criar adolescentes e jovens adultos. Rio de Janeiro: Editora Intrínseca, 2016.

KESSLER, Gabriel. A sensação de insegurança. Sociologia do medo do crime. $1^{\text {a }}$ ed. $1^{\text {a }}$ reimp. Buenos Aires: Siglo Veintiuno Editores, 2011.

LEAL, Luciana Nunes. Aumenta acesso de jovens a álcool e drogas, mostra pesquisa do IBGE. Jornal o Estado de São Paulo. Publicado em: 26 ago. 2016. Disponível em: <http://saude.estadao.com.br/noticias/geral,aumenta-acesso-de-jovens-a-alcoole-drogas-mostra-pesquisa-do-ibge,10000072030>. Acesso em: nov. 2017. 
MEDEIROS, Fernanda Cavalcanti de. A inserção da família no processo socioeducativo de adolescentes em privação de liberdade. 2015. $188 f$. Dissertação (Mestrado em Psicologia) - Centro de Ciências Humanas, Letras e Artes, Universidade Federal do Rio Grande do Norte, Natal, 2015.

MONTENEGRO, Fátima Maria Martins Barroso. Entre a ronda e a cana: os discursos sobre a criminalidade do jovem negro no final do século XIX. 2013. 106 f. Monografia (Bacharelado em Direito) - Universidade de Brasília, Brasília, 2013.

MORAES, Josiane. Sociedade contemporânea e adolescência em conflito com a lei: uma problematização da criminalização do adolescente. 2010.183 f. Trabalho de Conclusão de Curso (Graduação em Serviço Social) - Universidade Federal de Santa Catarina, Florianópolis, 2010.

MORÁS, Luis Eduardo. Jóvenes inservibles y menores incorregibles. Los residuos del crecimiento económico. In: PATERNAIN, Rafael; RICO Álvaro (coord.). Uruguay: Inseguridad, Delito y Estado. Montevideo: TRILCE, 2012.

OLIVEIRA, Ana Sofia Ferreira de Castro. A avaliação do risco de violência juvenil: um contributo para o seu estudo. Porto. 2015. 286 f. Tese (Doutorado em Psicologia) - Universidade do Porto, Porto, 2015.

OLIVEIRA, Juliana Proenço de. Plano nacional de cultura (lei no 12.343/2010): perspectivas históricas e constitucionais. 2014. 97 f. Trabalho de Conclusão de Curso (Graduação em Ciências Jurídicas e Sociais) - Universidade Federal do Rio Grande do Sul, Porto Alegre, 2014.

TEIXEIRA, Patrícia Santos. Adolescentes em semiliberdade: consumo de álcool e outras drogas e atendimento em uma unidade do interior do estado de São Paulo. 2014. 109 f. Tese (Doutorado em Educação) - Universidade Estadual Paulista, Faculdade de Filosofia e Ciências de Marília, 2014.

VALE, Cláudia Antônia da Silva Almeida. Significados e implicações da violência escolar: dissonância e consonâncias nas percepções das famílias e da escola. 
2015. 130 f. Dissertação (Mestrado em Economia Doméstica) - Universidade Federal de Viçosa, Viçosa. 2015.

\section{APÊNDICE}

Material aprovado pela Faculdade Internacional Signorelli, no ano de 2018, sob a orientação dos professores Thereza Christina e Denise Cardoso Garcia Nunes.

Enviado: Junho, 2021.

Aprovado: Junho, 2021. 